\title{
THE EVALUATION OF DYNAMIC COMPACTION ANALYSIS AS A QBD TOOL FOR PAEDIATRIC ORODISPERSIBLE MINITABLET FORMULATION
}

\author{
SONIA IURIAN *, LARISA ILIE, MARCELA ACHIM, IOAN TOMUȚĂ \\ Department of Pharmaceutical Technology and Biopharmacy, Faculty of Pharmacy, "Iuliu Hațieganu” University of
} Medicine and Pharmacy, 41 Victor Babeș Street, Cluj-Napoca, 400012, Romania

*corresponding author: sonia.iurian@umfcluj.com

Manuscript received: May 2020

\begin{abstract}
The formulation of orodispersible minitablets (ODMTs) usually targets the disintegration time and mechanical strength, but should also consider a series of technological issues related to powder flow and compression behaviour. In this regard, the present study aimed to evaluate the contribution of dynamic compaction analysis as Quality by Design (QbD) tool in ODMTs' formulation. Placebo tablets were prepared by direct compression following a design of experiments (DoE). Each powder blend was subjected to dynamic compaction analysis; the work of compression, the elastic recovery, the detachment stress, the ejection stress as well as the disintegration time and crushing strength were determined. The effects of input variables on the responses were quantified as regression models and two sets of constraints were applied for Design Space (DS) development: one regarding tablet characteristics and the second one including compression performance parameters. The DS was validated and the robust point and negative control were used to prepare ODMTs. Their characteristics confirmed the benefits of including the compression parameters into the early formulation stages of ODMTs.
\end{abstract}

\section{Rezumat}

Formularea minicomprimatelor orodispersabile (ODMT) vizează de obicei optimizarea timpului de dezagregare şi a rezistenței mecanice, dar ar trebui să ia în considerare și o serie de probleme tehnologice legate de curgerea amestecului de pulbere și de performanță a comprimării. În această privință, studiul de față a urmărit să evalueze contribuția analizei dinamice a comprimării ca instrument al conceptului de Calitate prin Design (QbD) în formularea ODMT. S-au preparat comprimate placebo prin comprimare directă după un plan experimental (DoE). Fiecare amestec de pulbere a fost supus unei analize dinamice de compactare; s-au determinat lucrul mecanic al comprimării, revenirea elastică, tensiunea de detaşare, tensiunea de ejecție, precum şi timpul de dezagregare și rezistența mecanică. Efectele variabilelor de intrare asupra răspunsurilor au fost cuantificate ca modele de regresie și s-au aplicat două seturi de constrângeri pentru dezvoltarea Domeniului Optim (DS): unul cu privire la caracteristicile tabletei, iar al doilea adăugând parametrii de performanță ai comprimării. DS a fost validat, iar punctul robust și controlul negativ au fost utilizate pentru prepararea ODMT. Caracteristicile lor au confirmat avantajele includerii parametrilor de performanță a comprimării în etapele de formulare a ODMT.

Keywords: Quality by Design, DoE, formulation development, tableting performance

\section{Introduction}

Paediatric therapy has drawn the attention of regulatory authorities in the drug domain because of the frequency of off-label and unauthorized medicines use in paediatric population. Drug prescribing in children is often based on extrapolation of results from data obtained in clinical trials performed on adults, because of the missing relevant data on children. Paediatric population is often deprived of adequate dosage forms and as a consequence, parents or caregivers refer to modifications to licensed drugs such as dispensing the drug in a different form, prepare drugs extemporaneously, crush tablets to prepare a suspension etc. Inpatient studies reported that off-label and unlicensed drug prescriptions in children ranged from $36.3 \%$ to $97 \%$, while in outpatient studies the proportion was lower, between $7 \%$ and $51.7 \%$ and could be associated with an increased risk of adverse drug reactions [16]. On the other hand, the pharmaceutical industry has been reluctant to perform clinical trials in children due to the ethical issues, the decreased commercial interest and the supplementary costs. As a response, the regulatory environment reformed the legislation to stimulate the research of child-appropriate medicines through the paediatric research equity act issued in USA in 2002 and EMA guidelines for paediatric medicines adopted in 2006 [6]. EMA defines age-appropriate medication as products whose pharmaceutical design makes them suitable for use in the target age groups, with respect to composition, dosage form, dosing frequency and packaging [21]. Their most important features are the efficacy and ease of use, the safety and accessibility for the patient [23]. 
The decision-making regarding the choice of the appropriate dosage form is difficult because of agerelated physiological differences and preferences [21]. A key consideration when children are involved is the acceptance of the medication, when factors like palatability and swallowability have to be well thoughtout [2]. In this respect, the research media points out that a risk- based approach aligned with the principles of Quality by Design (QbD) is essential at the development of a new product [25].

Oral liquid dosage forms used to be the gold standard for drug administration in children, in spite of the risk of inaccurate dosing, low stability, the large number of excipients and difficult transportation. Therefore, recent research works stated that solid oral dosage forms as multiparticulates, minitablets and orodispersible forms are more appropriate options, with flexible dosing and high stability [6]. Orodispersible minitablets were first reported by Stoltenberg and Breitkreutz (2011) as 2 - $3 \mathrm{~mm}$ diameter tablets that disintegrate in the oral cavity in a few seconds [24]. The risks associated to their administration like choking or aspiration are low and their acceptability and swallowability were confirmed in paediatric patients below 6 years of age [1].

However, a series of technological issues with impact on the balance between stability, mechanical properties and disintegration should be considered at the development of orodispersible minitablets, as well as the processability of the selected excipients and the compression performance.

The QbD approach in drug development is always in the search of new methods for a better characterization and understanding of products and processes. It relies on a series of tools such as risk assessment strategies, design of experiments (DoE), NIR spectroscopy and Raman spectroscopy that grant the thorough knowledge of products and processes [22]. Dynamic compaction analysis offers details on the compressibility, compactibility and tabletability of a powder, and enables the calculation of parameters related to the compression process performance, such as the detachment and ejection stress. Pitt et al. demonstrated its ability to predict tablet failure on rotary presses by measuring the ejection shear stress on small amounts of powder blends [20]. The development of a product in the QbD concept begins with establishing the Quality Target Product Profile (QTPP) and the more detailed and precise the quality profile, the lower the risks of failure. The QTPP usually includes essential characteristics of the finished pharmaceutical product [11]. However, the inclusion of relevant performance parameters of the preparation process could be useful in preventing manufacturing errors and material loss. This study aims at applying a risk reduction strategy for the optimization not only of tablet characteristics, but also of process performance parameters derived from the dynamic compaction analysis, from the early stages of formulation development. It started with the elaboration of the QTPP, the identification of the critical quality attributes (CQAs) of the product and their relations with the formulation factors and process parameters through an Ishikawa diagram. The preparation of placebo orodispersible tablets was guided by a DoE from which the effects of the input variables on the CQAs of the product but also of the compression process were quantified. The validation of the experimental plan was achieved by generating a Design Space (DS) to ensure the quality of the tablets, but also the smooth running of the compression. Finally, ODMTs were prepared in order to test the resulting hypotheses.

\section{Materials and Methods}

\section{Materials}

Ludiflash was kindly donated by BASF (Germany), magnesium stearate was purchased from Merk (Germany) and sodium stearylfumarate was obtained from JRS PHARMA (Germany).

\section{Risk management procedure}

In the need to gain a more systematic understanding of pharmaceutical products and processes, the International Conference for Harmonization document Q8 defined the QTPP as the first element of pharmaceutical development. It contains features of the pharmaceutical product related to its quality, safety and efficacy [9]. The QTPP led to the choice of CQAs which were further investigated for their dependence on Critical Process Parameters and Critical Material Characteristics through Ishikawa diagrams.

DoE

A design of experiments was developed for a better understanding of the effects of lubricants and of the compression force on the powders' and tablets' characteristics. Two lubricants were included into the study: sodium stearylfumarate (NaSf) and magnesium stearate $(\mathrm{MgSt})$, as a qualitative input variable (X1). Their ratios were evaluated in the domain $1 \%-4 \%$, as a quantitative factor (X2). The compression load, a process parameter with a high impact on the QTPP, was selected as a quantitative variable and ranged from $200 \mathrm{~kg}$ and $400 \mathrm{~kg}$ on three levels. A D-Optimal optimization design was generated (Modde 12.1, Sartorius, Sweden) with 19 runs, comprised of 15 individual experiments and 4 replicated centre points, as shown in the experimental design matrix, Table I. As response, a CQA corresponding to the powder blend was selected: the compressibility index (Y1). Four parameters that resulted from the compaction analysis were included as responses in the experimental design: the work of compression (J) (Y2), the elastic recovery (\%) (Y3), the detachment stress (MPa) (Y4) and the ejection stress (MPa) (Y5). The disintegration time (s) of the tablets and their hardness $(\mathrm{N})$ were set as responses Y6 and Y7. The same software was used for statistical calculations and data fitting. The influences of independent 
FARMACIA, 2020, Vol. 68, 6

variables on the responses were assessed using Multiple Linear Regression (MLR) method. Further, the same software was used to generate Design Spaces applying to different sets of constraints. A Design Space (DS) is described by a complex mathematical function and represents an area from the experimental domain where the input variables interact in such a way that the responses fit into the desired quality profile. Its calculation relies on the regression model equations and the estimation of the probability of failure $(\%)$, meaning the probability of making predictions outside the specifications [11]. DoE validation requires the testing of formulations from both inside and outside of the DS and the assessment of the experimental values compared to the predicted ones.

\section{Powder blend preparation}

$100 \mathrm{~g}$ of each of the powder mixtures were prepared using the corresponding quantities of Ludiflash ${ }^{\circledR}$ and lubricant, blended in a Y-shaped mixing vessel (Erweka Y5, Germany) with a capacity of $5 \mathrm{~L}$, at $30 \mathrm{rpm}$ for 10 minutes.

Flow properties of powders

Powder flow was assessed according to the European Pharmacopoeia (Eur. Ph.) 10.0, 2.9.36 [7]. The bulk density and the tapped density were determined for the further calculation of the compressibility Index (Carr's Index) (Y1).

Tablet preparation

Tablet preparation was performed using Gamlen tablet press (GTP, series D, Gamlen Tableting Ltd. Biocity Nottingam, UK). $100 \mathrm{mg}$ of each powder mixture listed in Table I were compressed using a flat punch with a diameter of $6 \mathrm{~mm}$, descending at a speed of $60 \mathrm{~mm} / \mathrm{min}$. Six samples of each formulation were compressed at three different loads: 200, 300 and $400 \mathrm{~kg}$.

ODMT preparation was performed using an eccentric tablet press (Korsch EK0, Germany) equipped with a $2 \mathrm{~mm}$ diameter set of punches adjusted at an average weight of $10 \mathrm{mg} / \mathrm{ODMT}$ using the powder blends and process parameters revealed by the optimization process.

Table I

Experimental design matrix

\begin{tabular}{ccccc}
\hline Experiment name & Run order & Lubricant type (X1) & Lubricant ratio (\%) (X2) & Compression load (kg) (X3) \\
\hline N1 & 12 & MgSt & 1 & 200 \\
N2 & 5 & MgSt & 1 & 400 \\
N3 & 17 & NaSf & 1 & 200 \\
N4 & 2 & NaSf & 1 & 400 \\
N5 & 9 & NaSf & 1 & 300 \\
N6 & 18 & MgSt & 2 & 300 \\
N7 & 15 & NaSf & 2 & 200 \\
N8 & 14 & NaSf & 2 & 400 \\
N9 & 6 & MgSt & 4 & 200 \\
N10 & 10 & MgSt & 4 & 400 \\
N11 & 16 & MgSt & 4 & 300 \\
N12 & 11 & NaSf & 4 & 200 \\
N13 & 13 & NaSf & 4 & 400 \\
N14 & 7 & MgSt & 3 & 200 \\
N15 & 8 & MgSt & 3 & 400 \\
N16 & 1 & NaSf & 3 & 300 \\
N17 & 19 & NaSf & 3 & 300 \\
N18 & 3 & NaSf & 3 & 300 \\
N19 & 4 & NaSf & 3 & 300 \\
\hline
\end{tabular}

\section{Compaction analysis}

Dynamic compaction analysis was performed on benchtop single-punch Gamplen tablet press (GTP, series D, Gamlen Tableting Ltd. Biocity Nottingam, UK). $100 \mathrm{mg}$ of each powder mixture were compressed using a flat punch with a diameter of $6 \mathrm{~mm}$, descending at a speed of $60 \mathrm{~mm} / \mathrm{min}$. Six samples of each formulation were compressed at three different loads: 200, 300 and $400 \mathrm{~kg}$.

The analysis comprised three stages: compression, detachment and ejection, during which the real time upper punch position and force were recorded. The Gamlen software returned the force $v s$. displacement profile for each of the three stages which was further used for various parameter calculation.
In the compression phase, the work of compression (Y2) was calculated as the area under the force $v s$. displacement curve and was determined using the areas of rectangles, as described by Draskovic et al. The elastic recovery (Y3) was evaluated indirectly from the punch position at maximum load in relation to the punch position at minimum compression load [5]. In the detachment phase, detachment stress (MPa) (Y4) was calculated as a ratio between the maximum detachment force and the compact surface area [5]. In the final stage, ejection stress (MPa) (Y5) was determined as the highest ejection force in the cycle divided by the compact diameter multiplied to the in-die thickness and to constant $\pi[5]$. 
FARMACIA, 2020, Vol. 68, 6

The solid fraction, compaction pressure ( $\mathrm{MPa}$ ) and tensile strength $(\mathrm{MPa})$ were calculated as described by Draskovic in order to plot the compressibility, compactibility and tabletability of the mixtures. The obtained compacts were evaluated for their thickness and diameter using a caliper.

Disintegration test

The disintegration test was performed according to Eur. $\mathrm{Ph}$. method, in $800 \mathrm{~mL}$ distilled water at $37 \pm 0.5^{\circ} \mathrm{C}$, using the compendial disintegration apparatus (Pharmatest, Germany). The test was performed in triplicate and the disintegration time values (Y6) were expressed as mean \pm standard deviation.

\section{Crushing strength test}

Crushing strength (Y7) was measured using the PharmaTest (Germany) hardness tester on three samples of each formulation. The values were expressed as mean \pm standard deviation.

Weight variation

Twenty ODMTs were weighed on an analytical balance (Kern ABS, Germany), in order to determine the weight variations. The results were expressed as mean \pm standard deviation.

\section{Results and Discussion}

\section{Risk management}

The development, manufacturing and administration of paediatric solid oral dosage forms are associated to certain degrees of risk, starting with the formulation selection, process robustness and ending with product acceptance and safety [3]. In this respect, the research media points out that a risk-based approach following the principles of $\mathrm{QbD}$ is essential at the development of new products, especially when paediatric patients are targeted [25]. Risk management strategies start by defining the QTPP of the desired product that gathers the quality attributes needed to meet its intended use. The QTPP shown in Table II was established by the authors after a thorough review of the published papers on minitablets and ODMTs.

Minitablets or ODMTs were feasible at diameters between $1 \mathrm{~mm}$ and $3 \mathrm{~mm}$, although Tissen et al. reported processability issues for the $1 \mathrm{~mm}$ tablets as tablet bisection by the scraper affecting $25 \%$ of the batch $[15,26]$. Acceptable mechanical properties of the tablets were reported at crushing strengths above $7 \mathrm{~N}$ or tensile strengths over $2 \mathrm{MPa}[15,24]$.

Table II

QTPP of placebo ODMTs

\begin{tabular}{|c|c|c|}
\hline QTPP element & Target & Observations \\
\hline Route of administration & Oral & \\
\hline Dosage form & Orodispersible minitablet & \\
\hline Dosage strength & Placebo & \\
\hline \multirow[t]{8}{*}{ Product quality attributes } & Diameter & $2-3 \mathrm{~mm}$ \\
\hline & Crushing strength & $\geq 7 \mathrm{~N}($ Stoltenberg et al. 2011$)$ \\
\hline & Disintegration time & $\leq 3$ minutes (Eur. Ph.), $\leq 30 \mathrm{~s}$ (USP) \\
\hline & Assay & Placebo product, not applicable \\
\hline & Dissolution & Placebo product, not applicable \\
\hline & Weight uniformity & Weight variation within the $\pm 10 \%$ limit (Eur. Ph.) \\
\hline & Content uniformity & Placebo product, not applicable \\
\hline & Taste, palatability & Pleasant taste, high palatability \\
\hline Container closure system & Suitable for storage in normal conditions & $\begin{array}{l}\text { Ensures product integrity during shelf life } \\
\text { Enables easy ejection and administration }\end{array}$ \\
\hline
\end{tabular}

The development and manufacturing of ODTs are often challenging tasks because of the need to establish a balance between the good disintegration properties in small volumes of liquid and sufficient mechanical resistance to withstand packaging, transport and administration. Therefore, most of the research studies found crushing strength, disintegration time and the active pharmaceutical ingredient's (API) release [4, 12] as critical quality attributes (CQAs) for these products. The weight uniformity is also critical for ODMTs as previous studies showed that weight variability increases when the tablet diameter decreases.

The Ishikawa diagram shown in Figure 1 lists the process, formulation and analytical method related factors that could influence the CQAs. One of the factors that could ensure consistent die filling and good weight uniformity in the case of ODMT preparation is good flowability. Appropriate lubrication can overcome the poor flowing properties, but it could also impact the disintegration and mechanical characteristics of compacts.

Compaction pressure could influence the compression process performance, detachment stresses, ejection stresses, but also the tablet's mechanical and disintegration characteristics.

The aforementioned sources of variability are the main risks at the preparation of ODMTs and one way to diminish their effects on the product is to evaluate them through an experimental design.

DoE

The correlation between formulation and process parameters and the powders' and tablets' CQAs were investigated through a DoE. The input variables that contributed to the DoE construction were chosen to impact both tablets' characteristics and the process performance. Ludiflash was chosen as a representative 
FARMACIA, 2020, Vol. 68, 6

of ODT direct compression co-processed fillers, as most of the ODT co-processed excipients like Pharmaburst ${ }^{\circledR}$ 500, Parteck ${ }^{\circledR}$ ODT or Pearlitol ${ }^{\circledR}$ Flash, Ludiflash $^{\circledR}$ contain mannitol as asoluble and pleasant tasting filler. It also contains polyvinyl acetate as binder and crospovidone as superdisintegrant which enables fast disintegration [14, 24]. Two lubricants were tested, magnesium stearate $(\mathrm{MgSt})$ and sodium stearylfumarate (NaSf) at levels comprised between
$1 \%$ and $4 \%$. Their use was previously mentioned in ODMTs' lubrication, MgSt is the most commonly used lubricant, while NaSf is a fatty acid ester which showed less interference with the tablet properties (tensile strength and disintegration) when compared to $\mathrm{MgSt}$ [27]. The use of MgSt was reported at concentrations between $0.25 \%$ and $5 \% \mathrm{w} / \mathrm{w}$, and the ratios of $\mathrm{NaSf}$ typically range between $0.5 \%$ and $2 \% \mathrm{w} / \mathrm{w}$ [27].

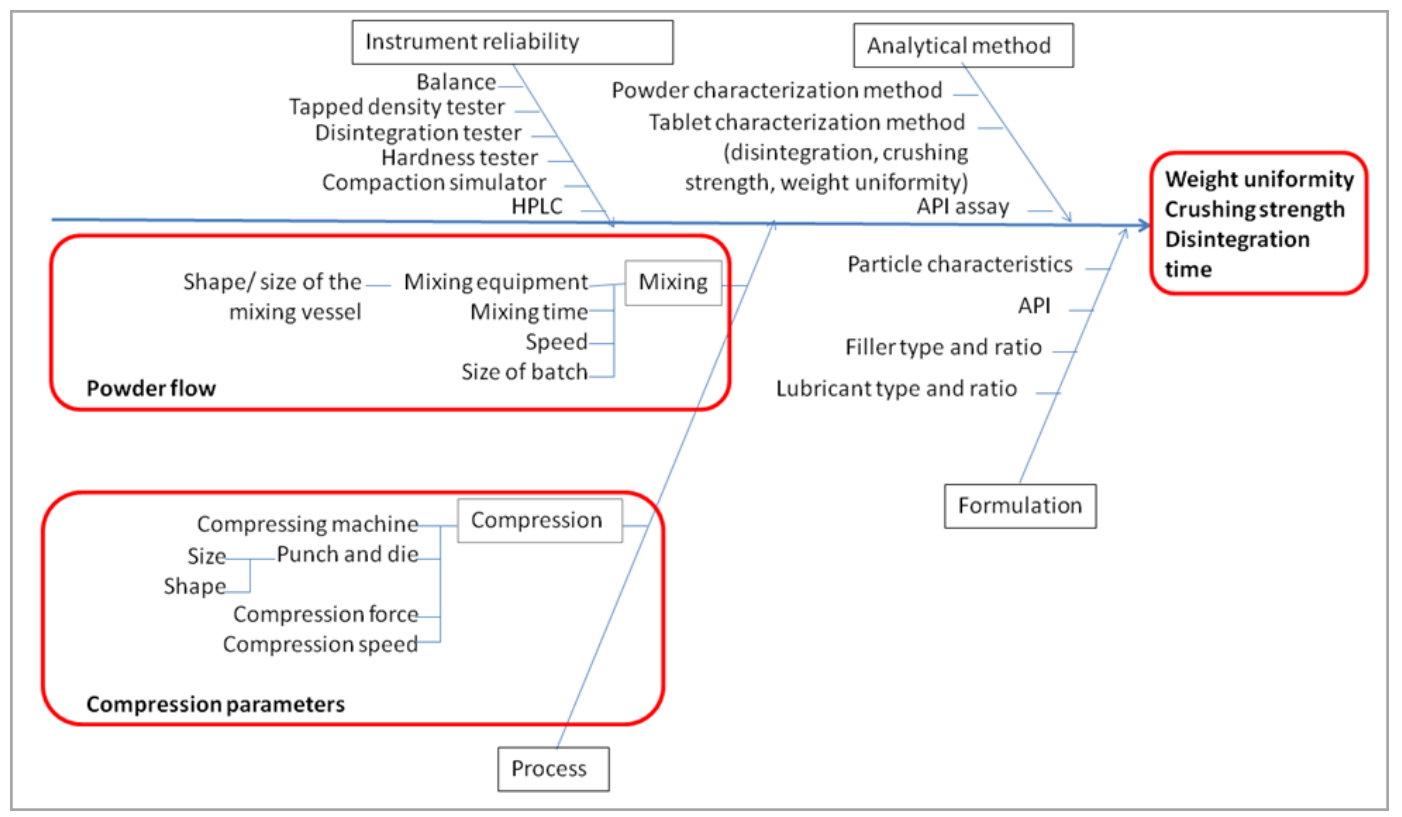

Figure 1.

Ishikawa diagram

The powder flow expressed as compressibility index was evaluated as a response in the experimental design because of its dependence on the type and ratio of lubricant and also on its impact on the ODMTs' CQAs. The tablets were prepared using a fully instrumented compression simulator in order to provide a full description of the compression, detachment and ejection stages. The calculated parameters were analysed as responses in the DoE, as well as the ODMTs' mechanical and disintegration properties.

\section{Quality of fit of experimental results}

The experimental data were fitted using Multiple Linear Regression (MLR) which leads to models that link process performance parameters and ODMTs' CQAs to the input variables. MLR finds the regression model which minimizes the residual sum of squares of the response variable [8]. The responses and the parameters that indicate the quality of the obtained models are listed in Table III. The $\mathrm{R}^{2}$ parameter represents the goodness of fit and reveals how well the regression model fits the raw data. It varies between 0 and 1 , where 1 indicates a perfect model and 0 indicates no model at all [8]. As shown in Table III, the regression models obtained for the responses are over 0.9 , excepting the $\mathrm{R}^{2}$ for the disintegration time, which was 0.822 .
But $\mathrm{R}^{2}$ alone is not enough to affirm the validity of a model, therefore $\mathrm{Q}^{2}$, the goodness of prediction was calculated to estimate the predictive power of the model. All the obtained values for $\mathrm{Q}^{2}$ were beyond 0.5 and the differences between the corresponding $\mathrm{R}^{2}$ and $\mathrm{Q}^{2}$ were not higher than $0.2-0.3$ which shows appropriate models. The model validity was above 0.25 for all responses, while the reproducibility was beyond 0.5 and showed a small replicate error in relation to the variability seen across the design. The outcome of the experimental design analysis is a model comprised of regression coefficients used to interpret the influence of factors. The regression coefficients were represented as scaled and cantered and indicate the response's variation when the factors are raised from their zero levels to their maximum levels.

Powder flow

The powder flow was assessed by an indirect method that measures the bulk density compared to the tapped density of the powder. The compressibility index (Y1) was calculated according to the European Pharmacopoeia and the results were compared to those listed into the scale of flowability [7]. They ranged from $12.7 \%$ which shows good flow properties to $21.4 \%$ for powders 
FARMACIA, 2020, Vol. 68, 6

with passable flowability. As shown in Figure 2a, the type of lubricant (X1) had the most important effect on Y1 with a negative influence from MgSt and a positive influence from $\mathrm{NaSf}$. The use of $\mathrm{MgSt}$ led to the lowest Y1 values from the data set, $12.7 \%$, associated to the best powder flow, while using NaSf determined high Y1 values, from $17.4 \%$ to $21.4 \%$. A non-linear correlation was obtained between Y1 and the lubricant ratio that shows that the extreme values from the tested range (the lowest and the highest) led to the best flow properties for both of the lubricants which is in accordance to other results that have reported higher lubrication efficiency for both $\mathrm{MgSt}$ and $\mathrm{NaSf}$ at ratios of $1 \%$, with a slightly better performance for MgSt [18]. Draskovic et al. (2018) reported a compressibility index of $21 \%$ for Ludiflash alone, associated to particles with irregular shapes [5].

Table III

Response matrix and quality of fit parameters

\begin{tabular}{|c|c|c|c|c|c|c|c|}
\hline $\begin{array}{l}\text { Experiment } \\
\text { Name }\end{array}$ & $\begin{array}{c}\text { Compressibility } \\
\text { Index } \\
\text { (Y1) }\end{array}$ & $\begin{array}{c}\text { Work of } \\
\text { compression } \\
\text { (Y2) }\end{array}$ & $\begin{array}{l}\text { Elastic } \\
\text { recovery } \\
\text { (Y3) }\end{array}$ & $\begin{array}{l}\text { Detachment } \\
\text { stress } \\
\text { (Y4) }\end{array}$ & $\begin{array}{l}\text { Ejection } \\
\text { stress } \\
\text { (Y5) }\end{array}$ & $\begin{array}{c}\text { Disintegration } \\
\text { time } \\
\text { (Y6) }\end{array}$ & $\begin{array}{l}\text { Crushing } \\
\text { strength } \\
\text { (Y7) }\end{array}$ \\
\hline N1 & 14.2 & 1145.33 & 6.07 & 2.08 & 1.7 & 41 & 27.55 \\
\hline $\mathrm{N} 2$ & 14.2 & 2162.85 & 9.98 & 3.63 & 2.66 & 105.5 & 63.8 \\
\hline N3 & 17.4 & 1237.72 & 5.59 & 1.24 & 0.74 & 13.5 & 36.4 \\
\hline N4 & 17.4 & 1978.73 & 10.98 & 2.14 & 1.52 & 26.18 & 68.65 \\
\hline N5 & 17.4 & 1597.89 & 8.36 & 2.12 & 1.23 & 25.57 & 51.35 \\
\hline N6 & 13.8 & 1671.73 & 9.04 & 2.78 & 1.62 & 77.5 & 54.8 \\
\hline N7 & 21.4 & 1123.83 & 6.51 & 1.42 & 0.7 & 17.6 & 36.85 \\
\hline N8 & 21.4 & 1974.48 & 10.94 & 1.95 & 1.1 & 57.1 & 65.1 \\
\hline N9 & 12.7 & 1095.82 & 6.23 & 0.8 & 0.57 & 34 & 31.3 \\
\hline N10 & 12.7 & 1818.71 & 11.6 & 1.32 & 1.07 & 134 & 53.65 \\
\hline N11 & 12.7 & 1475.05 & 8.93 & 1.05 & 0.85 & 233 & 42.65 \\
\hline N12 & 18.9 & 1100.19 & 6.13 & 1.34 & 0.44 & 36.76 & 31.05 \\
\hline N13 & 18.9 & 1813.76 & 11.36 & 1.79 & 0.79 & 84.12 & 58.9 \\
\hline N14 & 15.6 & 1134.56 & 6.11 & 1.25 & 0.69 & 48.7 & 30.8 \\
\hline N15 & 15.6 & 1848.9 & 11.42 & 1.42 & 1.3 & 78.5 & 54.2 \\
\hline N16 & 18.3 & 1543.92 & 8.64 & 1.76 & 0.74 & 34.2 & 48.85 \\
\hline N17 & 18 & 1500 & 8.8 & 1.6 & 0.82 & 28 & 46 \\
\hline N18 & 18.8 & 1563 & 8.4 & 1.74 & 0.76 & 42 & 51 \\
\hline N19 & 17.5 & 1580 & 8.2 & 1.9 & 0.7 & 33 & 42 \\
\hline \multicolumn{8}{|c|}{ Statistical parameter } \\
\hline Goodness of fit, $\mathrm{R}^{2}$ & 0.928 & 0.983 & 0.978 & 0.915 & 0.988 & 0.915 & 0.928 \\
\hline $\mathrm{R}^{2}$ adjusted & 0.900 & 0.976 & 0.971 & 0.873 & 0.979 & 0.889 & 0.908 \\
\hline $\begin{array}{l}\text { Goodness of } \\
\text { prediction, } \mathrm{Q}^{2}\end{array}$ & 0.839 & 0.955 & 0.957 & 0.741 & 0.946 & 0.832 & 0.861 \\
\hline Model validity & 0.594 & 0.635 & 0.702 & 0.480 & 0.597 & 0.753 & 0.857 \\
\hline Reproducibility & 0.961 & 0.989 & 0.984 & 0.964 & 0.991 & 0.926 & 0.909 \\
\hline
\end{tabular}

Dynamic compression analysis

The dynamic compression analysis assessed the three phases of the compression process and several parameters were calculated from the force-displacement curves and analysed as responses in the DoE (Y2 - Y5). The work of compression (Y2) and elastic recovery (Y3) were calculated out of the profiles generated in the compact consolidation phase. The total work necessary for particle rearrangement, deformation, fragmentation and new bond forming was calculated as the total work of compression. As expected, the most important effect was obtained from the applied target load, whose increase generated a significantly higher work of compression. The type of lubricant did not impact Y2, but the lubricant ratio increase determined a slight decrease in the response, with a lower magnitude compared to the effect of the target load. A significant interaction was also found between X2 and X3 which shows that increasing lubricant ratios in mixtures compressed at high target loads reduces the work of compression.

The elastic recovery (Y3) was first influenced by the target load, meaning that increasing the target load led to high values of Y3. A significant effect was also obtained for the lubricant ratio, showing that high lubricant contents generated higher Y3. However, no differences were seen between MgSt and NaSf.

The most important effect on the detachment stress (Y4) was generated by the lubricant content: higher ratios of lubricants determined the decrease of the Y4, but the behaviour of the tested lubricants was not similar: when using MgSt the Y4 values ranged from 0.8 to $3.63 \mathrm{MPa}$, while the use of NaSf led to Y4 values comprised between 1.24 and $2.14 \mathrm{MPa}$ (Figure $2 d)$. The interactive effect between $X 1$ and $X 2$ showed that high target loads of compression applied on mixtures with inferior percentages of MgSt generated important detachment stresses, but as the MgSt ratio raised, Y4 
FARMACIA, 2020, Vol. 68, 6

decreased significantly down to values close to $1 \mathrm{MPa}$ (Figure 3). The variation range of $\mathrm{Y} 4$ is narrower when $\mathrm{NaSf}$ is used, with the lowest values reached for minimum target load of compression or maximum lubricant ratio. However, all values were in the accepted range, below $3 \mathrm{MPa}$. Detachment stresses can be minimized either by applying low target loads, or by using high percentages of lubricants.
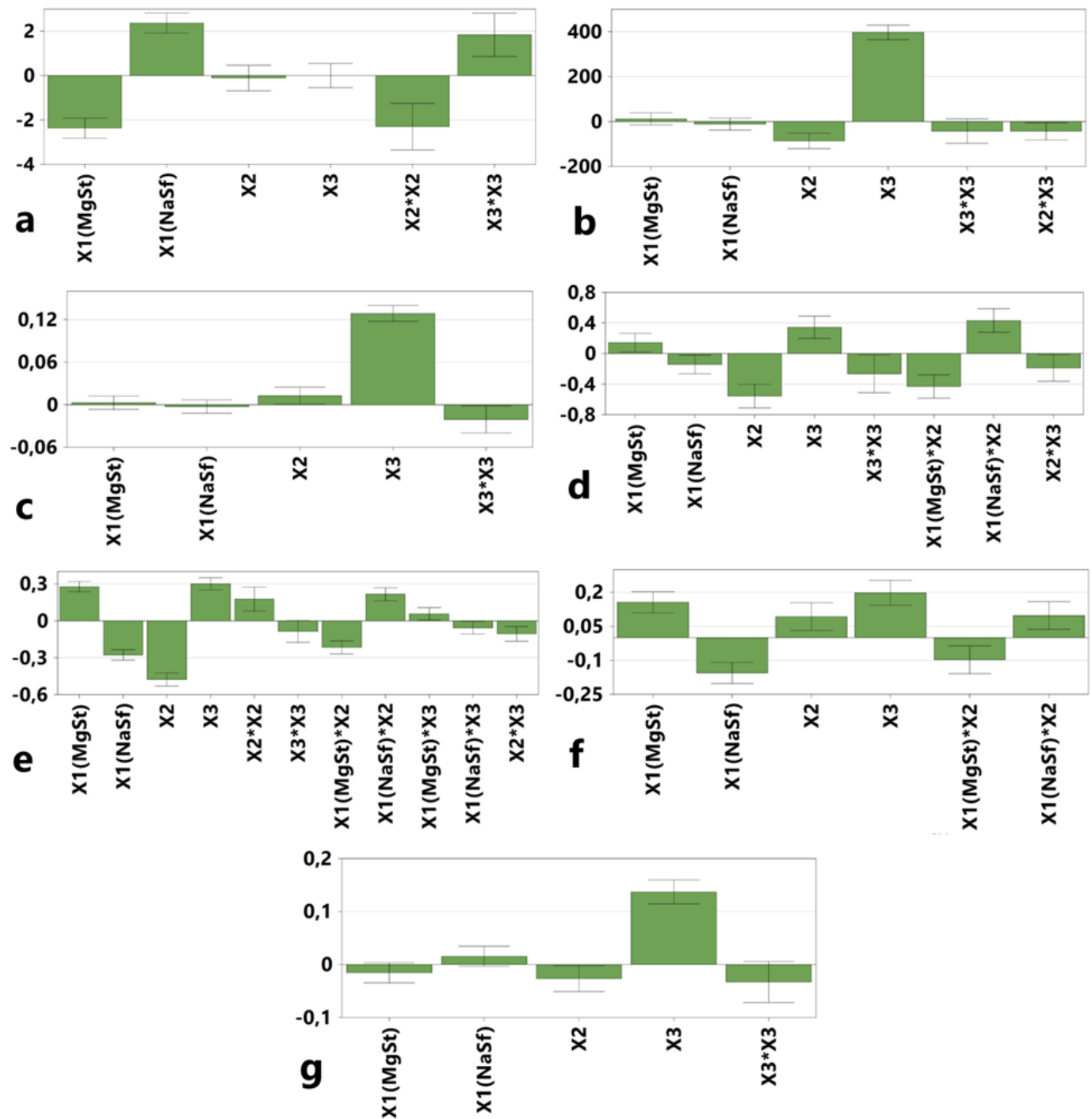

Figure 2.

The influence of input variables on: a, the compressibility index (Y1); b, the work of compression (Y2); c, elastic recovery (Y3); d, detachment stress (Y4); e, ejection stress (Y5); f, disintegration time (Y6); g, crushing strength (Y7), where $\mathrm{X} 1$ is the type of lubricant, $\mathrm{X} 2$ represents the lubricant ratio and $\mathrm{X} 3$ is the target load of compression
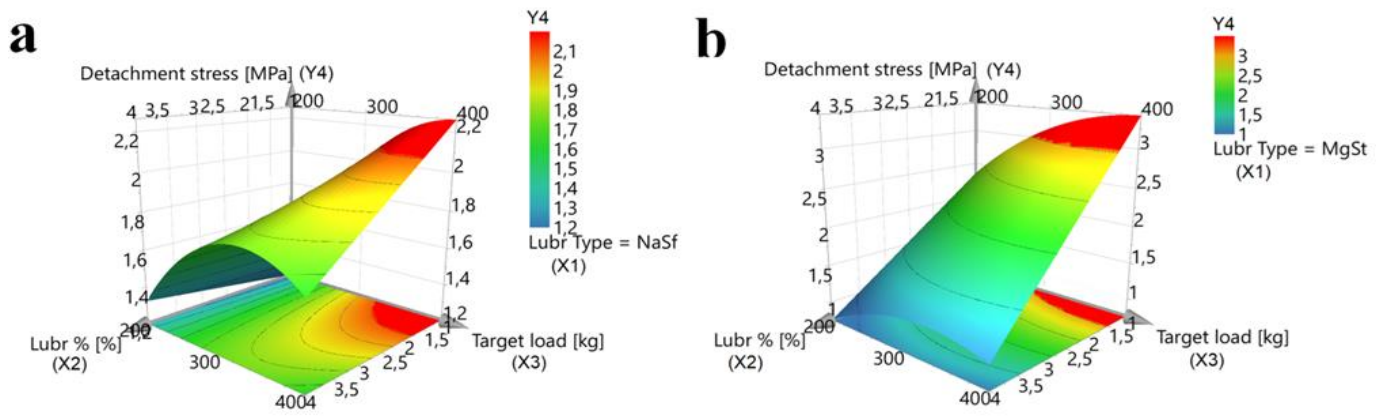

Figure 3.

Response surfaces of detachment stress (Y4) as a function of the lubricant ratio (X2) and the target load of compression (X3) for the two lubricants: NaSf (a) and MgSt (b) 

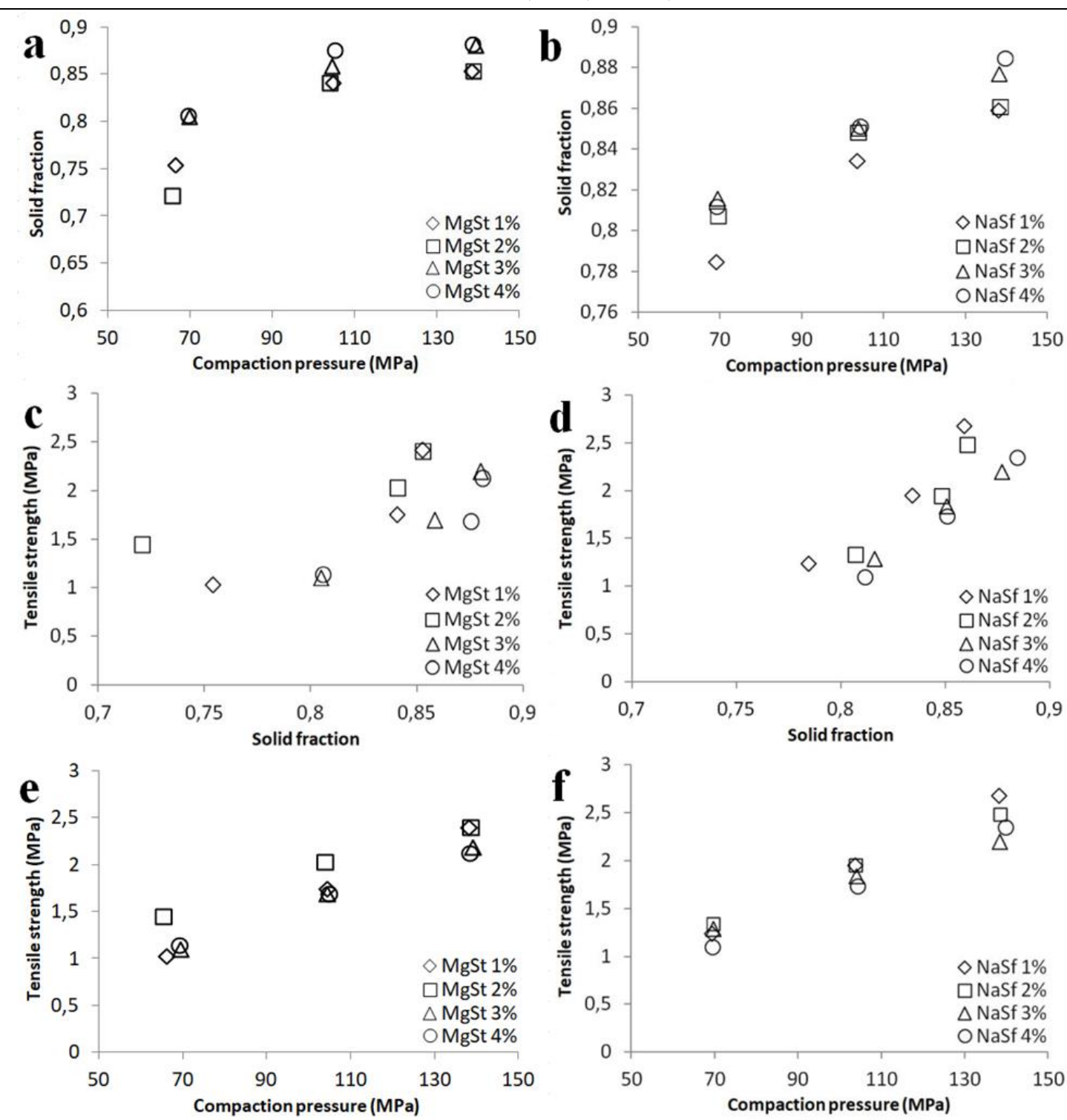

Figure 4.

Compressibility (a, b), compactibility (c, d) and tabletability (e, f) profiles of the evaluated mixtures

The ejection stresses (Y5) ranged between 0.44 and $2.66 \mathrm{MPa}$ and displayed a very similar effect pattern when compared to the one corresponding to the detachment stress (Figure 2e). The lubricant ratio exerted the most important influence on Y5: for both lubricants, the ratio increase led to Y5 decrease. The positive influence of $\mathrm{MgSt}$ is related to the coverage of the superior interval of Y5 variation, while NaSf produced mixtures with low Y5. The target load increase had a higher impact on mixtures with MgSt comparing with NaSf.

Out of the force $v s$. displacement profiles returned by the dynamic compression evaluation, the solid fraction, compaction pressure (MPa) and tensile strength (MPa) were calculated, as they best indicate the material compaction properties. Compressibility, compactibility and tabletability profiles were plotted as solid fraction $v s$. compaction pressure, tensile strength $v s$. solid fraction and respectively tensile strength $v s$. compaction pressure (Figure 4). It is well known that compaction pressure increase associated to high compact density and low porosity generates wetting and disintegration difficulties. To acquire fast disintegration, compact with low solid fractions should be obtained, in a range of $0.7-0.8$ [17]. The tested formulations displayed solid fractions between 0.72 and 0.89 , with the lowest value attained for the mixture containing $2 \% \mathrm{MgSt}$. The $2 \% \mathrm{MgSt}$, as well as the $1 \% \mathrm{NaSf}$ mixtures showed the highest compressibilities that go along with the good flow properties indicated by Carr's Index. Moreover, when force $v s$. displacement profiles were evaluated (data not shown), high displacement values were recorded for intermediate ratios of $\mathrm{MgSt}$ and low ratios of NaSf, which indicates a high volume reduction ability for those formulations.

The ability of powders to yield resistant compacts when exposed to a compression pressure is returned as a compactibility profile (Figures $4 \mathrm{c}$ and $4 \mathrm{~d}$ ), and the 
best compactibility was obtained when low ratios of both lubricants were used. Ludiflash also contains polyvinyl acetate as a binder, which contributes to enhance compactibility and could be responsible of levelling the lubricant effects [24].

Tensile strength limits are not officially defined by the pharmacopoeias, however ideally they should exceed $2 \mathrm{MPa}$ for highly robust products, or $1 \mathrm{MPa}$ for products that do not undergo important mechanical stresses [20]. The resulting compacts showed tensile strengths over $2 \mathrm{MPa}$ at solid fractions around 0.85 , while values over $1 \mathrm{MPa}$ were obtained at solid fractions between 0.7 and 0.8 . Formulations with $2 \% \mathrm{MgSt}$ and $1 \% \mathrm{NaSf}$ had the best tabletability profiles (Figures $4 \mathrm{e}$ and 4f). Apparently, high contents of lubricants do not improve tabletability, which is a measure of plastic deformation capacity.

Tablets' CQAs

The measured disintegration times (Y6) were between $13.5 \mathrm{~s}$ and $233 \mathrm{~s}$, while the maximum value allowed by the Eur. Ph. for orodispersible tablets is of $180 \mathrm{~s}$. Only one formulation containing 4\% MgSt out of 19 tested formulations was outside the accepted interval. As expected, the target load (X3) was the factor whose influence showed the highest magnitude, as its increase determined slower disintegration due to the high solid fraction determined by the load increase. The lubricant ratio (X2) also had a positive influence on the disintegration time: the increase in lubricant ratio led to long disintegration time, but this effect was stronger when high target loads were applied on the compressed blend, because of the low porosity that prevents water from wetting the structure.

MgSt led to the highest disintegration times, while NaSf gave formulations with fast disintegration (Figure 2f). The large surface area of MgSt combined with its hydrophobicity, hinder wetting and prevent water from penetrating the structure [13, 27].

The effects on crushing strength (Y7) are similar to those discussed for the tensile strength with the highest magnitude obtained for the compression load and a slight decrease at high amounts of lubricants.

Design Space development and DoE validation

The experimental domain of a study is defined by the variation limits of the input factors. Out of the experimental domain, the Design Space (DS) represents a sum of factor combinations that lead to the desired responses. The refined model equations obtained for each of the dependent variables are able to predict the responses with a particular degree of certainty, depending on their predictive capacity. DS development involves applying a series of constraints to the CQAs of the product, so that it complies with the Quality Target Product Profile.

As shown in Table IV, the first optimization regarded the tablets' characteristics: disintegration time and crushing strength. The targeted disintegration time was of $20 \mathrm{~s}$, with an accepted maximum value of $60 \mathrm{~s}$. As for the crushing strength, it was set for $55 \mathrm{~N}$, with a minimum value of $40 \mathrm{~N}$. The obtained DS covered more than half of the experimental domain and the risk to get predictions outside the specifications was assessed by the probability of failure (\%), which was below $2.5 \%$ in the green area (Figure 5a). The robust point (RP1) with $0 \%$ probability of failure was obtained at $\mathrm{X} 1=\mathrm{NaSf}, \mathrm{X} 2=2 \%$ lubricant ratio and X3 = 333.3 $\mathrm{kg}$ compression load.

Further, a second optimization was performed, adding constraints on the responses derived from the dynamic compaction analysis and powder flow evaluation (Table IV). Both detachment stresses and ejection stresses were limited to a maximum of $2 \mathrm{MPa}$. The compressibility index was set at a maximum value of $20 \%$. As, a result, the optimum area was significantly reduced (Figure $5 \mathrm{~b}$ ) and the robust point (RP2) was identified at $\mathrm{X} 1=\mathrm{NaSf}, \mathrm{X} 2=2,2 \%$ and $\mathrm{X} 3=266,6 \mathrm{~kg}$. Both of the generated DSs had NaSf as lubricant, which is in agreement with the findings of Stoltenberg et al.; applying the same constraints in the experimental domain obtained with $\mathrm{MgSt}$ led to an area with no robust points that meet the disintegration criteria [24]. An arbitrarily chosen point from that domain was used as negative control (NC) with X1 $=\mathrm{MgSf}, \mathrm{X} 2=1.2 \%$ and $\mathrm{X} 3=400 \mathrm{~kg}$. Table $\mathrm{V}$ reveals the results of the evaluation of the two optimal formulations, as well as those obtained for the negative control. The prediction capacity of the models was challenged by calculating the residual values; the differences between the experimental and the predicted values were small, usually below $10 \%$, except for the disintegration time, which is understandable due to the subjective evaluation of the disintegration endpoint (Table V). Both RP1 and RP2 comply with the conditions imposed by the QTPP for the orodispersible tablets, but the compression performance parameters were slightly higher for RP1. Usually, detachment and ejection stresses below 3 MPa ensure good mechanical properties and allow easy packaging and handling [5, 20]. Even values comprised between $3 \mathrm{MPa}$ and $5 \mathrm{MPa}$ are considered acceptable if the product does not undergo coating or other stressful processes. Therefore, considering that the detachment and ejection stress values of formulations RP1 and RP2 do not surpass the limit of $3 \mathrm{MPa}$, important differences with respect to compression process performance are not expected.

The NC formulation chosen from outside of the DS showed a long disintegration time of $102.33 \mathrm{~s}$ and a detachment stress over $3 \mathrm{MPa}$, which confirms the validity of the DS.

Up to this point of the study, the DSs were validated, which confirms the accuracy of the model equations and their predictive power. However, it is still unclear if the obtained results are relevant for the direct compression of minitablets. 
Table IV

Optimization criteria

\begin{tabular}{llccccccc}
\hline \multicolumn{1}{c}{ Response } & \multicolumn{3}{c}{ Optimization 1 } & \multicolumn{3}{c}{ Optimization 2 } \\
\cline { 2 - 8 } & Criterion & Minimum & Target & Maximum & Criterion & Minimum & Target & Maximum \\
\hline Compressibility Index (Y1) & Excluded & - & - & - & Minimize & - & 11 & 18 \\
Work of compression (Y2) & Excluded & - & - & - & Excluded & - & - & - \\
Elastic recovery (Y3) & Excluded & - & - & - & Excluded & - & - & - \\
Detachment stress (Y4) & Excluded & - & - & - & Minimize & - & 0.6 & 2 \\
Ejection stress (Y5) & Excluded & - & - & - & Minimize & - & 0.4 & 2 \\
Disintegration time (s) (Y6) & Minimize & - & 20 & 60 & Minimize & - & 20 & 60 \\
Crushing strength (Y7) & Maximize & 40 & 55 & - & Maximize & 50 & 55 & - \\
\hline
\end{tabular}

Table V

Design Space validation results

\begin{tabular}{lccccccccc}
\hline & \multicolumn{3}{c}{$\begin{array}{c}\text { Optimization 1 - Robust point } \\
\text { (RP1) }\end{array}$} & $\begin{array}{c}\text { Optimization 2 - Robust point } \\
\text { (RP2) }\end{array}$ & \multicolumn{3}{c}{$\begin{array}{c}\text { Negative control } \\
\text { (NC) }\end{array}$} \\
\cline { 2 - 9 } & Predicted Experimental & Residual & Predicted & Experimental & Residual & Predicted Experimental Residual \\
\hline $\begin{array}{l}\text { Compressibility Index } \\
\text { (\%) (Y1) }\end{array}$ & 18.84 & 19.10 & 0.26 & 18.98 & 19 & 0.02 & 14.31 & 14.03 & -0.28 \\
$\begin{array}{l}\text { Detachment stress } \\
\text { (MPa) (Y4) }\end{array}$ & 2.01 & 2.13 & 0.12 & 1.73 & 1.68 & -0.05 & 3.25 & 3.36 & 0.11 \\
$\begin{array}{l}\text { Ejection stress } \\
\text { (MPa) (Y5) }\end{array}$ & 1.00 & 0.92 & -0.08 & 0.77 & 0.72 & -0.05 & 2.46 & 2.46 & 0.00 \\
$\begin{array}{l}\text { Disintegration time } \\
\text { (s) (Y6) }\end{array}$ & 30.41 & 34.00 & 3.59 & 23.78 & 25.33 & 1.55 & 98.54 & 102.33 & 3.79 \\
$\begin{array}{l}\text { Crushing strength } \\
\text { (N) (Y7) }\end{array}$ & 55.43 & 57.00 & 1.57 & 44.55 & 46.87 & 2.32 & 61.50 & 63.27 & 1.77 \\
\hline
\end{tabular}

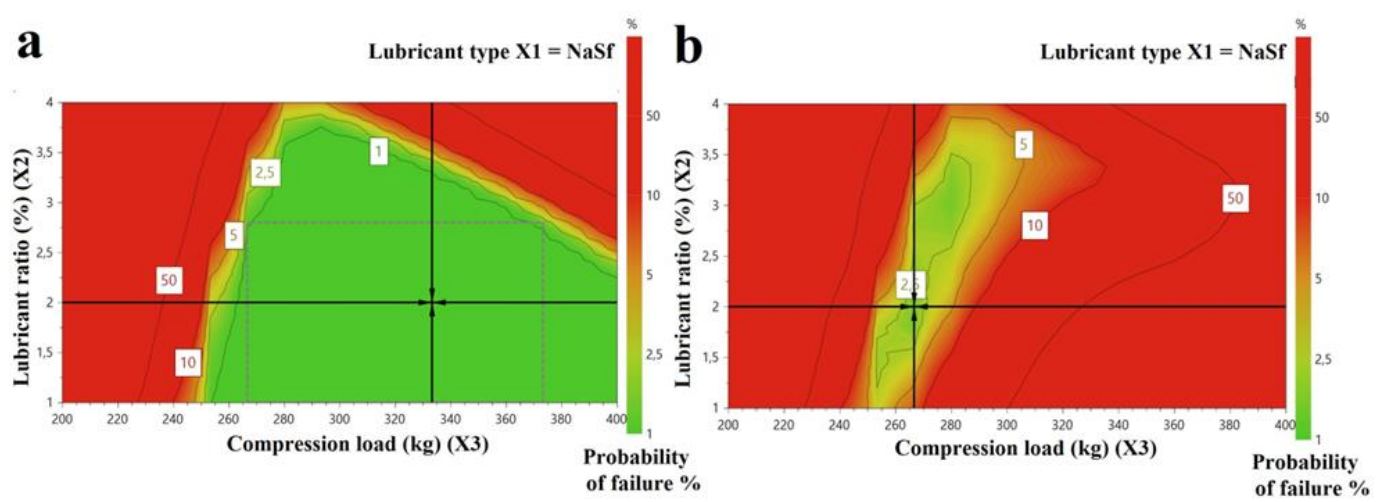

Figure 5.

Design Space for the placebo orodispesible tablets that meet the specifications for disintegration time and crushing strength (a) and for compressibility index, detachment stress, ejection stress, disintegration time and crushing strength (b), expressed as probability of failure as a function of the lubricant ratio (X2) and compression load (X3)

\section{Practical implications of the study}

Previous literature reports confirm that data provided by the dynamic compaction analysis coincide with those obtained with rotary tablet presses, despite important differences in tablet weight and shape; however it seems that the incidence of defects was lower on the rotary press [20]. In order to establish whether the DoE approach and the previously described DSs are efficient in guiding the preparation of orodispersible minitablets by direct compression, minitablets with a diameter of $2 \mathrm{~mm}$ were prepared, starting from the two formulations, RP2 from the DS and NC from outside the DS.

Minitablets were evaluated for the same CQAs, crushing strength and disintegration time and for their weight uniformity. As shown in Table VI, the disintegration time was significantly higher for the NC minitablets than for the RP2 formulation, which is in accordance with the previous results.

The crushing strength was higher for the NC formulation, but the values displayed a larger variation range. Also, it should be considered that this crushing strength of $33.84 \mathrm{~N}$ was attained at a high compression load that in the long run could be damaging for the sensitive multiple punches [24].

RP2 minitablets displayed a uniform aspect, matte, with no colour variations and regular sizes (Figure 6a). NC minitablets had a glossy, compact appearance, with black marks on the outer surface (Figure 6b), which indicate strong interactions between the compression 
material and the walls of the dye and difficulties in ejection. These phenomena can be correlated to the high values of detachment and ejection stresses that left the NC formulation outside the DS and ignoring them could lead to more serious compression defects like capping or lamination. Such compression errors could be avoided by designing the formulation and keeping the process safe within the limits of the Design Space. Therefore, these results suggest that the parameters derived from the dynamic compaction analysis could be useful from the early phases of the development to predict and avoid further manufacturing errors and material loss.

\begin{tabular}{lcccc}
\hline & RP2 minitablets & RSD $(\%)$ & NC minitablets & RSD $(\%)$ \\
\hline Crushing strength (N) & $17.69 \pm 1.22$ & 6.94 & $33.84 \pm 4.70$ & 13.9 \\
Disintegration time (s) & $20.5 \pm 3.27$ & 15.95 & $121.63 \pm 10.14$ & 10.14 \\
Average weight (mg) & $9.59 \pm 0.19$ & 1.98 & $10.29 \pm 0.18$ & 1.76 \\
\hline
\end{tabular}

* Results are expressed as mean \pm standard deviation; RSD, relative standard deviation.

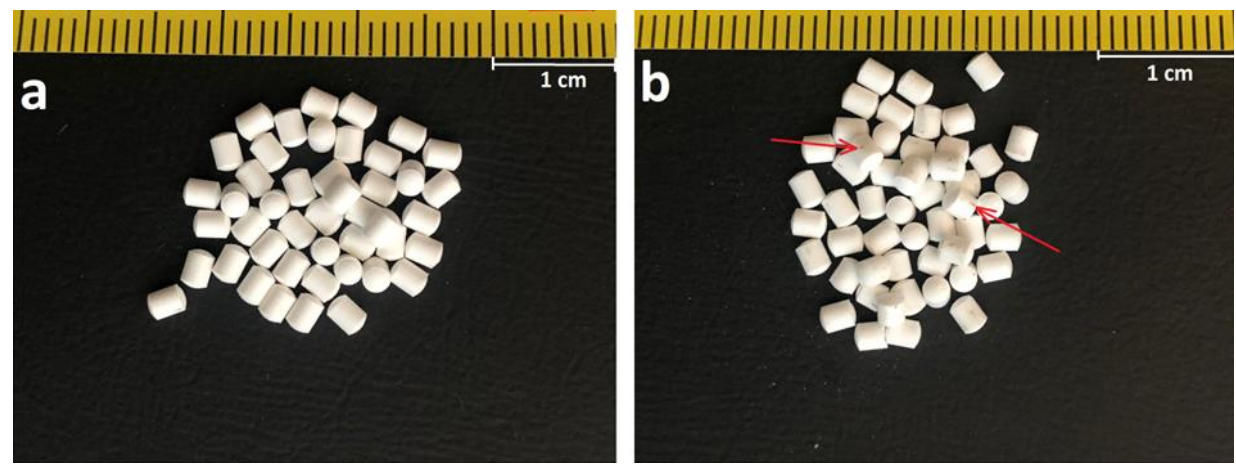

Figure 6.

Orodispersible minitablets prepared according to the Design Space validation results: RP2 minitablets contain $\mathrm{X} 1=\mathrm{NaSf}, \mathrm{X} 2=2.2 \%$ and were compressed at X3 $=266.6 \mathrm{~kg}$ compression load (a) and NC minitablets contain $\mathrm{X} 1=\mathrm{MgSf}, \mathrm{X} 2=1.2 \%$ and were compressed at X3 $=400 \mathrm{~kg}$ compression load (b)

Of course, the study has a number of limitations, primarily the absence of the drug substance. However, it is known that each product has its own particularities, depending on the properties of the active substance (particle size, size distribution, particle shape, crystallinity), on the excipients and on the interactions between them. For example, Ludiflash was previously associated with APIs known for their different compression properties, with herbal extracts and with solid lipid pellets and each time different results were obtained in terms of disintegration and resistance [19], but the compression variables were more or less neglected.

\section{Conclusions}

This study aimed to test the hypothesis that the inclusion of compression performance parameters in the design as critical features is useful from the earliest stages of formulation and it confirmed that dynamic compression analysis makes this possible in a short time and with low substance use, when integrated into a risk based QbD approach. The proposed strategy fits perfectly into the $\mathrm{QbD}$ concept since the process functioning and the product quality are predicted in the first phases of the design.

Other practical information revealed by this study is related to the differences between the behaviours of the two lubricants. Apparently they perform the same functions, but nevertheless exert different effects on the associated powders. MgSt led to powders with significantly better flow than NaSf, but also led to increased forces required for detachment and ejection of the compact and disintegration times. So it could ensure complete filling of the mould, respectively uniformity of weight and content, but the resulting tablets could be subjected to fractures and slow disintegration.

Regarding the selection of the percentage of lubricant in the mixture, the results indicate the possibility of correcting a high elastic recovery, but also the forces of detachment and ejection, by supplementing the lubricant. On the contrary, the disintegration time can be kept to a low value by using a small percentage of any of the lubricants, but the one that produces a weaker hydrophobic effect is NaSf.

\section{Acknowledgement}

This paper was published under the frame of European Social Found, Human Capital Operational Programme 2014-2020, project no. POCU/380/6/13/125171.

\section{Conflict of interest}

The authors declare no conflict of interest. 


\section{References}

1. Bajcetic M, de Wildt SN, Dalinghaus M, Breitkreutz J, Klingmann I, Lagler FB, Keatley-Clarke A, Breur JMPJ, Male C, Jovanovic I, Szatmari A, Ablonczy L, Burckhardt BB, Cawello W, Kleine K, Obarcanin E, Spatenkova L, van der Meulen M, Wagner P, Walsh J, Laer S, Orodispersible minitablets of enalapril for use in children with heart failure (LENA): Rationale and protocol for a multicentre pharmacokinetic bridging study and follow-up safety study. Contemp Clin Trials Commun., 2019; 15: 100393: 1-8.

2. Bowles A, Keane J, Ernest T, Clapham D, Tuleu C, Specific aspects of gastro-intestinal transit in children for drug delivery design. Int J Pharm., 2010; 395(1-2): 37-43.

3. Casian T, Iurian S, Bogdan C, Rus L, Moldovan M, Tomuta I, QbD for pediatric oral lyophilisates development: risk assessment followed by screening and optimization. Drug Dev Ind Pharm., 2017; 43(12): 1932-1944.

4. Casian T, Bogdan C, Tarta D, Moldovan M, Tomuta I, Iurian S, Assessment of oral formulation-dependent characteristics of orodispersible tablets using texture profiles and multivariate data analysis. J Pharm Biomed Anal., 2018; 152: 47-56.

5. Draskovic M, Djuris J, Ibric S, Parojcic J, Functionality and performance evaluation of directly compressible co-processed excipients based on dynamic compaction analysis and percolation theory. Powder Tech., 2018; 326(3): 292-301.

6. Drumond N, van Riet-Nales DA, Karapinar-Carkit F, Stegemann S, Patients' appropriateness, acceptability, usability and preferences for pharmaceutical preparations: results from a literature review on clinical evidence. Int J Pharm., 2017; 521(1-2): 294-305.

7. Edqm.eu. European Pharmacopoeia, $10^{\text {th }}$ ed. EDQM, European Pharmacopoeia, Council of Europe, 2019, www.edqm.eu/en/european-pharmacopoeia.

8. Eriksson L, Johansson E, Kettaneh-Wold N, Wikstrom $\mathrm{C}$, Design of experiments, principles and applications, $3^{\text {rd }}$ edition, Umetrics Academy, Umea, 2008.

9. Fda.gov., Guidance for Industry Q8(R2) Pharmaceutical Development. Silver Spring: U.S. Department of Health and Human Services Food and Drug Administration; 2016, www.fda.gov/media/71535.

10. Hirschberg C, Sun CC, Rantanen J, Analytical method development for powder characterization: Visualization of the critical drug loading affecting the processability of a formulation for direct compression. J Pharm Biomed Anal., 2016; 128: 462-468.

11. Iurian S, Tomuta I, Bogdan C, Rus L, Tokes T, BarbuTudoran L, Achim M, Moldovan M, Leucuta S, Defining the design space for freeze-dried orodispersible tablets with meloxicam. Drug Dev Ind Pharm., 2016; 42(12): 1977-1989.

12. Iurian S, Bogdan C, Tomuta I, Szabo-Revesz P, Chvatal A, Leucuta SE, Moldovan M, Ambrus R, Development of oral lyophilisates containing meloxicam nanocrystals using QbD approach. Eur J Pharm Sci., 2017; 104: 356-365.

13. Kuno Y, Kojima M, Nakagami H, Yonemochi E, Terada K, Effect of the type of lubricant on the characteristics of orally disintegrating tablets manufactured using the phase transition of sugar alcohol. Eur $J$ Pharm Biopharm., 2008; 69(3): 986-992.

14. Lura A, Luhn O, Gonzales JS, Breitkreutz J, New orodispersible mini-tablets for paediatric use - A comparison of isomalt with a mannitol based co-processed excipient. Int J Pharm., 2019; 572: 118804: 1-11.

15. Mitra B, Thool P, Meruva S, Aycinena JA, Li J, Patel J, Patel K, Agarwal A, Karki S, Bowen W, Decoding the small size challenges of mini-tablets for enhanced dose flexibility and micro-dosing. Int J Pharm., 2020; 574: 118905: 1-11.

16. Moulis F, Durrieu G, Lapeyre-Mestre M, Off-label and unlicensed drug use in children. Therapie, 2018; 73(2): 135-149.

17. Mullarney MP, Hancock BC, Improving the prediction of exceptionally poor tableting performance: an investigation into Hiestand's "special case". J Pharm Sci., 2004; 93(8): 2017-2021.

18. Paul S, Sun CC, Systematic evaluation of common lubricants for optimal use in tablet formulation. Eur J Pharm Sci., 2018; 117: 118-127.

19. Petrovick GF, Kleinebudde P, Breitkreutz J, Orodispersible tablets containing taste-masked solid lipid pellets with metformin hydrochloride: Influence of process parameters on tablet properties. Eur J Pharm Biopharm., 2018; 122: 137-145.

20. Pitt KG, Webber RJ, Hill KA, Dey D, Gamlen MJ, Compression prediction accuracy from small scale compaction studies to production presses. Powder Tech., 2015; 270: 490-493.

21. Ranmal SR, O’Brien F, Lopez F, Ruiz F, Orlu M, Tuleu C, Walsh J, Liu F, Methodologies for assessing the acceptability of oral formulations among children and older adults: a systematic review. Drug Discov Today, 2018; 23(4): 830-847.

22. Rus LM, Iurian S, Kacso I, Borodi G, Porav S, Hegheş SC, Iuga CA, Tomuţă I, Development of meloxicam oral lyophilisates: role of thermal analysis and complementary techniques. Farmacia, 2019; 67(1): 56-67.

23. Standing JF, Tuleu C, Paediatric formulations-getting to the heart of the problem. Int J Pharm., 2005; 300(1-2): 56-66.

24. Stoltenberg I, Breitkreutz J, Orally disintegrating mini-tablets (ODMTs) - A novel solid oral dosage form for paediatric use. Eur J Pharm Biopharm., 2011; 78(3): 462-469.

25. Ternik R, Liu F, Bartlett JA, Khong YM, Thiam Tan DC, Dixit T, Wang S, Galella EA, Gao Z, Klein S, Assessment of swallowability and palatability of oral dosage forms in children: report from an M-CERSI pediatric formulation workshop. Int J Pharm., 2018; 536(2): 570-581.

26. Tissen C, Woertz K, Breitkreutz J, Kleinebudde P, Development of mini-tablets with $1 \mathrm{~mm}$ and $2 \mathrm{~mm}$ diameter. Int J Pharm., 2011; 416(1): 164-170.

27. Wang J, Wen H, Desai D, Lubrication in tablet formulations. Eur J Pharm Biopharm., 2010; 75(1): 1-15. 